\title{
Serum Phosphate - A Need to Revise Clinical Guidelines?
}

\section{Skulberg A*}

\author{
Anesthesiologist, Sorgenfrigt 11, N 0367 Oslo, Norway
}

*Corresponding author: Skulberg A, M.D., Anesthesiologist, Sorgenfrigt 11, N 0367 Oslo, Norway, E-mail: andreas.skulberg@getmail.no

\author{
Citation: Skulberg A (2016) Serum Phosphate - A Need to Revise Clinical Guidelines? J Anesth Pati Care \\ 1(1): 105. doi: 10.15744/2456-5490.1.105
}

\section{Received Date: January 19, 2016 Accepted Date: April 07, 2016 Published Date: April 08, 2016}

\section{Introduction}

This paper does not present new experimental data. It is based on existing literature and 40 years of clinical experience as an anesthesiologist. Author believes that it is necessary to look into clinical guidelines for some common, but serious medical conditions. It is not uncommon among clinicians to believe that serum phosphate is not as relevant as other electrolytes. In this paper author tried to argue why we should focus more on serum phosphate.

Serum phosphate $\mathrm{PO}_{4}$ is a critical constituent of all body tissues. It is involved in intermediate fat, carbohydrates and protein metabolism. It is of importance for the acid base balance. Adenosine-tri-phosphate (ATP) which contains the highly energy PO $_{4}$ bond, is consumed in the process of muscle contraction, neurologic functions and membrane electrolyte transport [1]. $\mathrm{PO}_{4}$ is only $1 \%$ of total phosphorus in the body. $15 \%$ of the inorganic $\mathrm{PO}_{4}$ are bound to proteins [1]. Phosphates move fast across the cell membrane. Acidosis cause more free phosphates, alkalosis reduces free phosphates. Respiratory changes cause greater changes than metabolic. Hyperventilation causes alkalosis and reduces serum phosphate significantly [1].

Oxygen is bound as hemoglobin to red blood cells in the lungs. To release oxygen from hemoglobin in the capillary circulation, di-phospho-glyserat (2,3 DPG) must be available. The concentration of free oxygen is proportional with 2,3 DPG which in turn is proportional with phosphate in the plasma and intracellular $\mathrm{PO}_{4}[1]$. A patient might have normal oxygen saturation, but if $\mathrm{PO}_{4}$ is low, 2,3 DPG is low and oxygen release from hemoglobin is seriously disturbed. This might cause hypoxia on the cellular level, - and in the worst case the patient dies.

"Adenosine-tri-phosphate (ATP), which contains the high energy $\mathrm{PO}_{4}$ bond, is consumed in the process of muscle contraction, neurologic functions, and membrane electrolyte transport" [1]. This means that athletes who exercise hard may have low values of phosphates. Sport drinks should contain phosphate. The effect of high phosphate in the blood you can see after training in high altitudes. People living in the mountains have high serum phosphate. People living in the lowland need time to gradually adapt to high altitudes. It is important for human beings to have the same oxygen values whether they live at sea level or up in the mountains.

There is a competition between glucose and oxygen in the body when serum phosphate and serum glucose is very low. Glucose must be bound to phosphate to cross the cell membrane and enter into cells. Release of phosphate from glucose inside the cell, happens only when glucose is metabolized using oxygen. Seriously low serum glucose combined with seriously low serum phosphate might be a life threatening condition as seen in serious malnutrition. Clinical guidelines for treatment of severe anorexia nervosa underline the importance of giving the patient phosphate and glucose simultaneously. Another example that shows the importance of this is what happened when prisoners released from concentration camps during World War 2 were given chocolate and died immediately [2]. Chocolate caused increased serum glucose, phosphate was bound to glucose and they did not have enough to also release oxygen from hemoglobin and acute cellular hypoxia caused death.

More common than low serum phosphate and low glucose, is low phosphate and normal glucose. This is called "PO ${ }_{4}$ Depletion Syndrome". In the book Fluids and Electrolytes possible symptoms from $\mathrm{PO}_{4}$ Depletion Syndrome are listed [1]:

\section{Insidious and Gradual Onset of Signs and Symptoms}

- Neuropsychiatric: Decreased mentation, memory loss, neuropathy, ataxia

- Constitution: Lethargy, malaise, debility

- Musculoskeletal: Weakness, myalgia, and subclinical myopathy, Arthralgia, joint stiffness, bone disease and subclinical osteomalacia

- Hematologic: Dysfunctions of platelets, red and white blood cells 
- Endocrine/Metabolic: Diminished tissue sensitivity to insulin, Increased production of 1,25 di(OH)D

- Renal: Glycosuria, hypercalciuria, hypermagnesiuria, RTA.

- Gastrointestinal: Anorexia, dysphagia

- Cardiopulmonary: Tachypnea, shallow respiration, decreased vital capacity, Decreased cardiac contractility, reduced sensitivity by peripheral vessels to vasoactive hormones

\section{Acute and Sudden Onset of Signs and Symptoms}

- Confusion, seizure, deliriums, and coma

- Acute cardiac de-compensation, hypotension

- Rhabdomyolysis

- Pulmonary insufficiency

- Generalized systemic de-compensation due to tissue, hypoxia and ATP deficiency.

As seen above, symptoms of $\mathrm{PO}_{4}$ Depletion Syndrome are numerous and often non-specific. If the clinician is not aware of what consequences low serum phosphate might cause, the diagnosis might easily be overseen. I believe we can improve diagnostics and treatment if several clinical guidelines are revised:

\section{Conclusions}

1. Clinical guidelines for routine/standard blood tests should include serum phosphate in the same way as we always measure serum sodium and potassium

2. Patients with respiratory failure/pulmonary insufficiency should have both oxygen and phosphate. (ask about kidney failure first, if so check serum phosphates before giving phosphates. Second: Give phosphate solution orally to patients with respiratory problems)

3. Patients with cardiac arrest should have intravenous infusion of phosphate during resuscitation

4. Patients with "The $\mathrm{PO}_{4}$ Depletion Syndrome" should be given phosphate.

\section{References}

1. Lau K (1986) Phosphate Disorders in Kokko JP et Tannen RL. Fluids and Electrolytes. W.B. Saunders Company 400, 398,417,426.

2. Skulberg A (2009) Glucose - a potential killer. Acta Anaesthesiol Scand 53: 684.

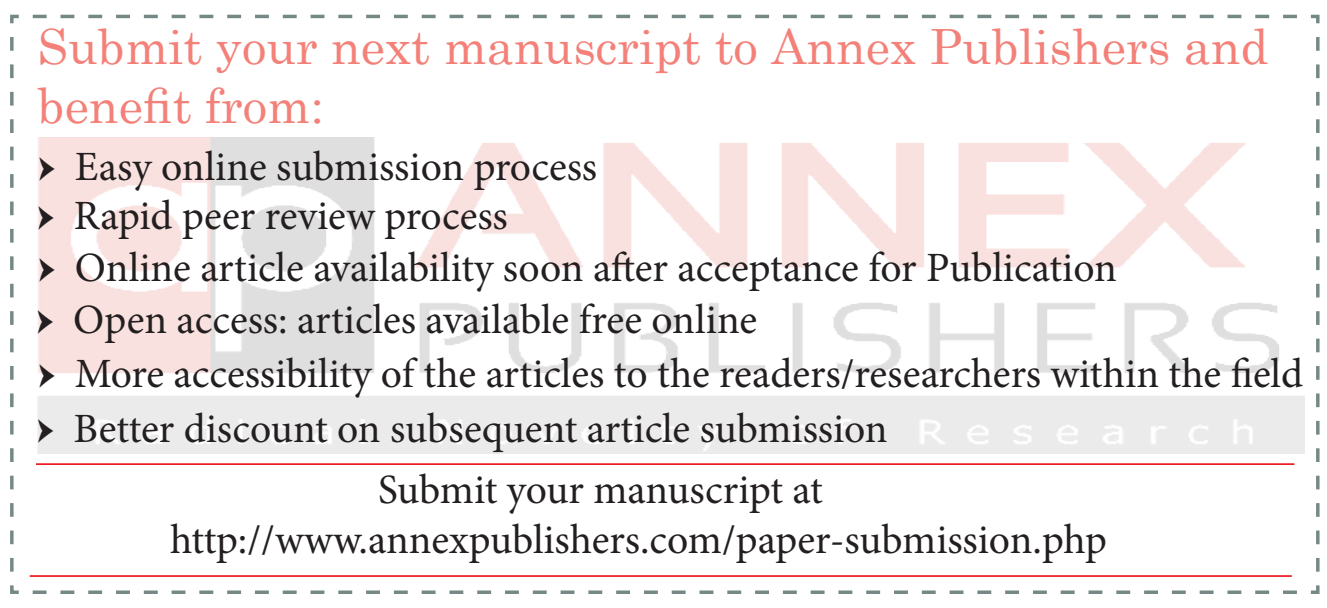

